\title{
Exploring the pharmacological potential of promiscuous host-defense peptides: from natural screenings to biotechnological applications
}

\section{Osmar N. Silva ${ }^{1,2}$, Kelly C. L. Mulder ${ }^{1}$, Aulus E. A. D. Barbosa ${ }^{1}$, Anselmo J. Otero-Gonzalez ${ }^{3}$, Carlos Lopez-Abarrategui ${ }^{3}$, Taia M. B. Rezende ${ }^{1}$, Simoni C. Dias ${ }^{1}$ and Octávio L. Franco ${ }^{1,2 *}$}

\author{
Programa de Pós-Graduação em Ciências Genômicas e Biotecnologia, Centro de Análises Proteômicas e Bioquímicas, Universidade Católica de Brasília, Brasília \\ Brazil \\ 2 Programa de Pós-Graduação em Genética e Biotecnologia, Universidade Federal de Juiz de Fora, Juiz de Fora, Brazil \\ ${ }^{3}$ Centro de Estudios de Proteínas, Facultad de Biología, Universidad de La Habana, La Habana, Cuba
}

\section{Edited by:}

Mirian A. F. Hayashi, Universidade Federal de São Paulo, Brazil

\section{Reviewed by:}

Atte Von Wright, University of Eastern Finland, Finland

Adam Paul Roberts, University

College London, UK

Sonia Alexandra Mendo, University of

Aveiro, Portugal

Jun Liu, Mount Sinai School of

Medicine, USA

Dmitri Debabov, NovaBay

Pharmaceuticals, USA

${ }^{*}$ Correspondence:

Octávio L. Franco, Pos-Graduação em Ciencias Genomicas e Biotecnologia, Centro de Analises Proteomicas e Bioquimicas, SGAN 916N, Modulo C Avenue W5, Asa Norte, Sala 219, Distrito Federal, Brasilia 71837-360, Brazil.

e-mail:ocfranco@gmail.com
In the last few years, the number of bacteria with enhanced resistance to conventional antibiotics has dramatically increased. Most of such bacteria belong to regular microbial flora, becoming a real challenge, especially for immune-depressed patients. Since the treatment is sometimes extremely expensive, and in some circumstances completely inefficient for the most severe cases, researchers are still determined to discover novel compounds. Among them, host-defense peptides (HDPs) have been found as the first natural barrier against microorganisms in nearly all living groups. This molecular class has been gaining attention every day for multiple reasons. For decades, it was believed that these defense peptides had been involved only with the permeation of the lipid bilayer in pathogen membranes, their main target. Currently, it is known that these peptides can bind to numerous targets, as well as lipids including proteins and carbohydrates, from the surface to deep within the cell. Moreover, by using in vivo models, it was shown that HDPs could act both in pathogens and cognate hosts, improving immunological functions as well as acting through multiple pathways to control infections. This review focuses on structural and functional properties of HDP peptides and the additional strategies used to select them. Furthermore, strategies to avoid problems in large-scale manufacture by using molecular and biochemical techniques will also be explored. In summary, this review intends to construct a bridge between academic research and pharmaceutical industry, providing novel insights into the utilization of HDPs against resistant bacterial strains that cause infections in humans.

Keywords: host-defense peptides, innate immunity, microbial infections, antimicrobials

\section{INTRODUCTION}

Infectious diseases caused by fungi and bacteria have affected humanity since the early days of civilization. Nevertheless, the discovery of penicillin by Fleming (1929) provided a potent defense in mammalian survival against pathogens. Based on penicillin, several other molecules and different antibiotic classes have been developed. However, all these agents have lost efficiency and are becoming useless against resistant bacterial strains.

Antimicrobial peptides (AMPs) have arisen as an alternative strategy for the treatment of infections caused by super bugs (Arias and Murray, 2009). AMPs are natural antibiotics found in microorganisms, plants, and animals (Hancock and Chapple, 1999). They can be structurally classified, being formed by $\alpha$ helices, $\beta$-sheets, extended structures, or disordered loops. Moreover, these peptides could also be classified by physical-chemical properties: cationic, anionic, and amphipathic (Peters et al., 2010). Mostly, cationic AMPs show their antimicrobial activity as a result of lipid bilayer disruption. Nevertheless they may also act on various cell targets, in some cases being considered promiscuous molecules (Huang et al., 2010). In the last few years the conventional idea that peptides possess an unconditional structure directly related to a particular function clashes with the peptide's ability to change and develop new functions. Considering these contrasting ideas, the knowledge of peptide promiscuity, in which multiple functions may be associated with a sole structure, has been gaining consideration in several research fields including the development of antibiotics. Indeed, several AMPs have shown their wide range of functions that are able to control numerous target pathogens simultaneously and in different conditions (as reviewed by Franco, 2011). Moreover, some peptides, in addition to activity against pathogens, also have shown multiple activities related to host innate immunity, called host-defense peptides (HDPs; Hancock et al., 2006).

Host-defense peptides are relatively small compounds, with 12-50 amino acid residues, positive net charge $(+2$ to +9$)$, and are isolated from single-celled microorganisms, invertebrates, plants, amphibians, birds, fishes, and mammals including humans (Hancock and Sahl, 2006). Furthermore, HDPs are classified 
into various groups according to a three-dimensional structure arrangement that includes $\alpha$-helices (magainin, cecropin, and cathelicidin), $\beta$-sheets (hepcidin, human $\alpha$-defensin 1 ), a mixture of $\alpha$-helices $/ \beta$-sheets (human $\beta$-defensins 1 ), cyclic (cyclotides and catestatin), as well as extended and flexible loops (e.g., indolicidin; Figure 1; Hancock et al., 2006). In addition to their direct action against microorganisms, as previously described, HDPs also present activities related to innate immunity. These include the induction or modulation of pro-inflammatory cytokine and chemokine production, chemotaxis, apoptosis, inflammatory response inhibition, recruitment, and stimulation of proliferation of macrophages, neutrophils, eosinophils, T lymphocyte activation, and differentiation of dendritic cells (DCs; Bowdish et al., 2005; Nijnik et al., 2009). One property that makes HDPs extremely attractive molecules for therapeutic use is that they are, in general, non-toxic to mammalian cells. The basis for this selectivity appears to be related to the lipid composition of the target membrane (fluidity, negative charge, and the absence/presence of cholesterol; Nicolas, 2009). The negative charge of a bacterial outer membrane is an example of a typical HDP target. In contrast, zwitterionic membranes, commonly found in plants and animals are not normally accessible to HDPs (Matsuzaki, 1999; Zasloff, 2002). Furthermore, the presence of cholesterol in the membrane may usually reduces HDP activity, since cholesterol helps in lipid bilayer stabilization, thus reducing membrane fluidity and flexibility (Matsuzaki, 1999).

This concept, in addition to peptide promiscuity, adds remarkable value to peptide antibiotic compounds, which have been shown to be much more useful for an organism's protection than merely membrane disruptors. The phenomenon of protein promiscuity, in which several functions are associated with a single peptide structure, has gained attention in several research fields, especially in the area of drug design (Franco, 2011). From this perspective, this review focuses on these compounds from various sources in order to shed some light on the structure and the observed mechanism of action. Furthermore, biotechnological and pharmaceutical potential will also be evaluated and discussed, as well as isolation and production in large-scale.

\section{PLANT HOST-DEFENSE PEPTIDES}

Plants have an arsenal of peptides in their own primitive innate immune system that is completely different from that of animal systems. Since plants are unable to synthesize antibodies, these peptides form an efficient barrier against bacteria, fungi, and insects. Furthermore, along with these peptides, plants have a set of physical and chemical barriers that act together to prevent infection (Sels et al., 2008). The plant cell wall is the first level of defense, formed by a complex network of proteins and polysaccharides. Even during a pathogen attack, plants are able to deposit callose, otherwise known as the polysaccharide $\beta$-1,3-glucan, at the infection site and further synthesize lignin-like polymers, thus reinforcing the wall (Hématy et al., 2009). Callose is a polysaccharide that acts in response to multiple biotic and abiotic stresses, as well as during a variety of processes in plant development (Chen and Kim, 2009). When a pathogen crosses through the cell wall, plants can induce a hypersensitive response (HR) or synthesize antibacterial and antifungal compounds for infection control. HR is characterized by an induced cell death at the point of pathogen contact and can be related to resistance (Mur et al., 2008). The antimicrobials produced are: ROS, secondary metabolites, proteins, and peptides were found (Benko-Iseppon et al., 2010).

In addition to providing a primary defense function, several plant peptides have shown a side biological property that could be exploited for biotechnological applications. This ability, in which a single structure provides multiple functions, has been denominated peptide promiscuity (Franco, 2011). Several plant peptides that show medicinal properties include defensins, thionins, and cyclotides. These peptides have shown a wide diversity of simultaneous activities, in addition to antibacterial and antifungal properties, which includes anti-HIV (Wong and $\mathrm{Ng}$, 2006), antitumor (Lin et al., 2010), leishmanicidal (Berrocal-Lobo et al., 2009), uterotonic (Gran, 1973), anthelmintic (Colgrave et al., 2009), and neurotensin blocking activities (Witherup et al., 1994). However, no plant peptide was found to have both simultaneous antimicrobial and immunomodulatory activities in mammals, clearly limiting the classification of HDPs into the plant kingdom. Nevertheless, we believe that this lack of immunomodulatory activity is related to the low quantity of studies in this field and not to the intrinsic properties of these promiscuous peptides in plants.

Plant AMPs show common properties that are characterized by a low molecular mass (around $10 \mathrm{kDa}$ ), cationic charge, and the presence of cysteine residues that are linked through disulfide bonds, thus stabilizing the molecular structure (Padovan et al., 2010). However, defensins, cyclotides, and thionins have specific and typical structures that will be described below.

Defensins are ubiquitous peptides in plant species, showing several nuanced functions (Padovan et al., 2010). Defensins are cationic peptides with pI values around 9.0 and are 45-55 amino acids residues long, with molecular masses ranging between 5 and $7 \mathrm{kDa}$ (Carvalho Ade and Gomes, 2009). The common tertiary structure consists of a triple-stranded antiparallel $\beta$-sheet, and one $\alpha$-helix which in most cases is stabilized by either three, four, or five disulfide bonds (Figure 2A; Garcia-Olmedo et al., 1998). The primary sequence is low conserved between different defensins, and this may explain the diverse biological activities reported (Padovan et al., 2010). Some of the defensins can be classified as promiscuous peptides (Franco, 2011) having multiple-biological functions (Table 1). In addition to defensins, thionins are peptides with low molecular masses $(5 \mathrm{kDa}), 45-47$ amino acid residues in length and can present three or four conserved disulfide bonds that stabilize the structural fold (Padovan et al., 2010). Due to their sequences and disulfide bonds patterns, thionins are classified into five structural types (I-V). The conserved structure is formed by two antiparallel $\alpha$-helices, one $\beta$-turn, and one antiparallel $\beta$-sheet (Figure 2B; Padovan et al., 2010). Some thionins demonstrated unusual biological functions (Table 1).

Finally, cyclotides are small peptides characterized by 28-37 amino acids long, presenting three disulfide bonds, and a cyclic backbone formed through the linking of amino and carboxylterminus (Craik, 2010). This structure confers to the cyclotides a strong and stable molecular structure (Figure 2C). Although $M$. cochinensis trypsin inhibitors have been classified as cyclotides due 


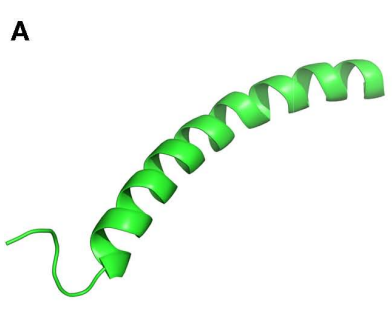

Human cathelecidin LL-37

D

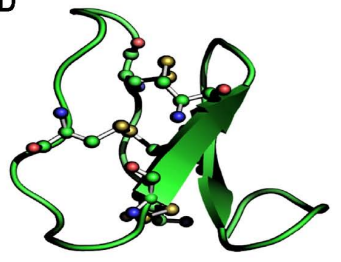

Kalata B2
B

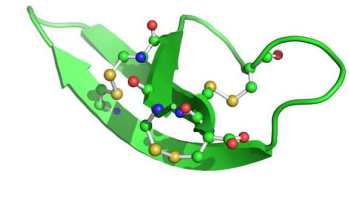

Human $\alpha \cdot$ defensin 1
C

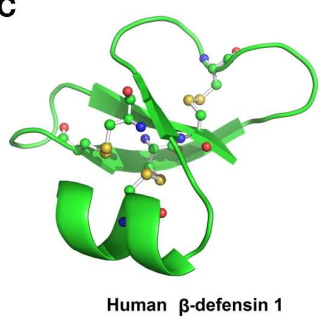

E

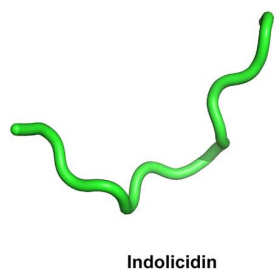

Indolicidin

FIGURE 1 |An overview of the major structural classes of host-defense peptides including (A) $\alpha$-helices, (B) $\beta$-sheets, (C) a mixture of $\alpha$-helices/ $\beta$-sheets structures, (D) cyclic, and (E) extended structures. Disulfide bonds are represented in ball and stick.

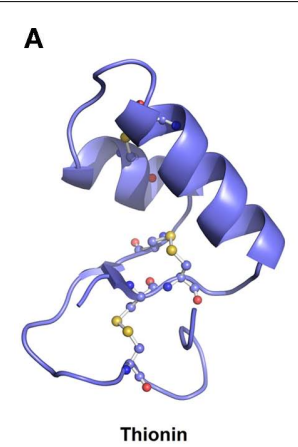

B
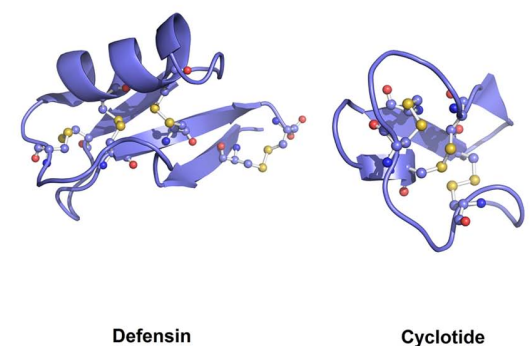

Cyclotide

FIGURE 2 |Three-dimensional structures of plant antimicrobial peptides. (A) Defensin - Vigna radiata defensin-2, (B) Thionin - Viscum album viscotoxin A3, and (C) Cyclotide - Viola odorata violacin A. Disulfide bonds are represented in ball and stick.

to their structural similarities, they do not display sequence homology to the previously identified plant cyclotides (FelizmenioQuimio et al., 2001). Until now, cyclotides were found in Violaceae, Rubiaceae, Apocynaceae, Cucurbitaceae, Poaceae, and Fabaceae families (Craik, 2010). Despite their conserved molecular structures, these cyclic peptides have shown diverse biological functions in addition to insecticidal activity (Table $\mathbf{1}$ ).

\section{HOST-DEFENSE PEPTIDES AND THEIR MULTIPLE ROLES IN ANIMAL IMMUNE DEFENSE}

Previously, it was believed that the direct antimicrobial activity of AMPs was essential for their role in innate immunity and hostdefense. However, some studies have shown that peptide concentrations found in various body parts, such as mucous for example, are relatively low when compared with those used in in vitro studies (Hirsch et al., 2008). It has been known that, in addition to this

activity against pathogens, HDPs may also have an indirect antimicrobial effect, as previously cited (Auvynet and Rosenstein, 2009). The human cathelicidin LL-37 (hCAP18), a well-characterized multifunctional HDP, is constitutively produced by leukocytes and induced in barrier organs upon inflammation and infection, thus being essential for immune response to injury and tissue infection (Bowdish et al., 2005). Another well-characterized HDP is the human $\beta$-defensin-2 (hBD2). It is known that this peptide plays an important role in immune response at different mucosal surfaces and also in the skin barrier (Ganz, 2003). Among the LL-37 and hBD2 wide activities spectrum, the induction of histamine and prostaglandin D2 released by mast cells after stimulating HDPs have important roles in microbial invasion response (Niyonsaba et al., 2001). Concomitantly to these activities, LL-37 induces keratinocytes to release IL- $1 \beta$, IL- 8 , TNF- $\alpha$, IL-6, colony-stimulating factor and granulocyte-macrophage (GM-CSF), and immature DCs to release TNF- $\alpha$ and IL-6 (Braff et al., 2005). However, the peptide response is dependent on the cell type that is studied. For example, in human peripheral blood mononuclear cells (PBMCs), LL-37 inhibits the expression of pro-inflammatory molecules, such as TNF- $\alpha$ and IL-6, and nuclear translocation of $\mathrm{NF \kappa B}$ p50/p65 induced by toll-like receptor (TLR)-2 and TLR-4 in response to lipoic acid (LA) and lipopolysaccharide (LPS), respectively. This inhibition is an important event in severe microbial infections, such as sepsis (Mookherjee et al., 2006). In addition, the hBD2 also acts on TLRs, functioning as an endogenous TLR-4 ligand, further activating immature DCs, and triggering a strong Th1 response (Biragyn et al., 2002).

Moreover, other not-so-well-studied peptides also act significantly on the mammal immune system. Human $\alpha$-defensins (HNP-1, HNP-2, and HNP-3) and $\beta$-defensins (hBD3 and hBD4) are involved in neutrophil and monocyte recruitment, while mast cells may be attracted to the infection site by LL-37, HNP-1-3, and hBD2 (Chen et al., 2007). Besides, human $\alpha$-defensins and $\beta$ defensins are chemotactic for immature DCs and memory T cells 
Table 1 | Plant HDPs and their multiple activities related to host-protection.

\begin{tabular}{|c|c|c|c|c|}
\hline Peptide name & Source & Activity & Possible application & Reference \\
\hline \multicolumn{5}{|l|}{ DEFENSINS } \\
\hline- & Phaseolus angularis & Inhibit tumor cell lines L121 and MBL2 & Antitumor therapy & Ma et al. (2009) \\
\hline Limenin & P. limensis & $\begin{array}{l}\text { Inhibit myeloma (M1) and leukemia (L1210) cell } \\
\text { lines and inhibit HIV-1 reverse transcriptase }\end{array}$ & $\begin{array}{l}\text { Antitumor and antiviral } \\
\text { therapy }\end{array}$ & Wong and $\mathrm{Ng}$ (2006) \\
\hline Lunatusin & P. lunatus & $\begin{array}{l}\text { Inhibit breast cancer cell line (MCF-7), the activity } \\
\text { of HIV-1 reverse transcriptase, and the translation } \\
\text { in a cell-free rabbit reticulocyte lysate system }\end{array}$ & $\begin{array}{l}\text { Antitumor and antiviral } \\
\text { therapy }\end{array}$ & Wong and $\mathrm{Ng}$ (2005) \\
\hline- & P. vulgaris & $\begin{array}{l}\text { Inhibit hepatom (HepG2), breast (MCF-7), colon } \\
\text { (HT29), and cervical cancer (SiHa) cells, and } \\
\text { inhibit HIV-1 reverse transcriptase activity }\end{array}$ & $\begin{array}{l}\text { Antitumor and antiviral } \\
\text { therapy }\end{array}$ & Lin et al. (2010) \\
\hline \multicolumn{5}{|l|}{ THIONINS } \\
\hline Without name & Triticum aestivum & Inhibit the proliferation of Leishmania donovani & $\begin{array}{l}\text { Leishmanicidal } \\
\text { therapy }\end{array}$ & Berrocal-Lobo et al. (2009) \\
\hline PTH1 & Solanum tuberosum & Inhibit the proliferation of $L$. donovani & $\begin{array}{l}\text { Leishmanicidal } \\
\text { therapy }\end{array}$ & \\
\hline \multicolumn{5}{|l|}{ CYCLOTIDES } \\
\hline Kalata B1 & Oldenlandia affinis & $\begin{array}{l}\text { Uterotonic, anti-HIV activities, and anthelmintic } \\
\text { activity against parasites of sheep, humans, and } \\
\text { dogs }\end{array}$ & $\begin{array}{l}\text { Anthelmintic, antiviral, } \\
\text { and uterotonic therapy }\end{array}$ & $\begin{array}{l}\text { Gran (1973), Colgrave et al. (2008), } \\
\text { Colgrave et al. (2009) }\end{array}$ \\
\hline Kalata B6 & O. affinis & $\begin{array}{l}\text { Anthelmintic activity against gastrointestinal par- } \\
\text { asites of sheep, humans, and dogs }\end{array}$ & Anthelmintic therapy & $\begin{array}{l}\text { Colgrave et al. (2008), Colgrave } \\
\text { et al. (2009) }\end{array}$ \\
\hline CirA & Chassalia parvifolia & Anti-HIV activity & Antiviral therapy & Gustafson et al. (1994) \\
\hline CirB & C. parvifolia & Anti-HIV activity & Antiviral therapy & \\
\hline Cyclopsychotride & Psychotria longipes & Ability to block neuropeptide neurotensin & Antipsychotic therapy & Witherup et al. (1994) \\
\hline Cycloviolacin $\mathrm{O} 2$ & Viola biflora & In vitro antitumor activity & Antitumor therapy & Gerlach et al. (2010) \\
\hline
\end{tabular}

(Yang et al., 2002), where human $\alpha$-defensins selectively induce the migration of human cells $\mathrm{CD} 4^{+}, \mathrm{CD} 45^{+}$, and $\mathrm{CD} 8^{+}$naive, suggesting that HDPs play an important role in mobilizing and amplifying the innate and adaptive immunity against microbial invasions (Yang et al., 2001). Indolicidin, for example, inhibits TNF- $\alpha$ secretion by macrophages in response to LPS treatment (Bowdish et al., 2005). Similar to the effects of LL-37, indolicidin induces the production of IL- 8 in human bronchial epithelial cells $16 \mathrm{HBE} 14 \mathrm{o}^{-}$. They also have demonstrated that the peptide bactenecin 2A, a member of bactenecins family, presented chemotactic activity over TH1 cells. Dermcidin-1L, another HDP example, stimulates keratinocytes to secrete TNF- $\alpha$, IL-8, CXCL10, and CCL20 (Niyonsaba et al., 2009). Another group of peptides with strong antimicrobial activity and immunomodulatory activity are protegrins. Protegrins- 1 and -3 promote rapid and efficient mature IL-1 beta release. Both peptides also promote modification in the morphology of monocytes and a loss of latency of the cell membranes (Perregaux et al., 2002).

Recent data have shown that HDPs are multifunctional molecules at different tissue levels, acting in the neuroendocrine system. Cathelicidins and defensin mRNA were widely found in the brain (Su et al., 2010), suggesting that HDPs could be involved in innate immune brain defense. Recently, it has been discovered that some neuropeptides play an important role in antimicrobial activity. Enkelytin, a pro-enkephalin-derived peptide, has shown strong activity against Gram-positive bacteria and also has acted as a link of communication and interaction between nervous, endocrine, and immune systems (Goumon et al., 1996). Met5-enkephalin peptide stimulated the proliferation of natural killer cells, B- and T-lymphocytes, migration of monocytes, lymphocytes, and neutrophils, and also stimulated the secretion of IL- 6 by monocytes (Kamphuis et al., 1998). Recently, Shan et al. (2011) suggested that Met5-enkephalin appeared to be involved in the regulation between the neuroendocrine and immune systems, modulating several cell functions related to innate and adaptive immunity. They also have found that Met5-enkephalin activated CD4 + T cells by increasing the expression of delta receptors. Moreover, this peptide also induced DC maturation through the expression of surface molecules (MHC class II, CD86, CD40), stimulated the production of IL-12, and down-regulated the intracellular acid phosphatases (ACP) in DCs. In addition, Met5-enkephalin (alone or in combination with either IL-2 or IFN- $\gamma$ ) up-regulated the proliferation of CD4 $+\mathrm{T}$ cells and increased production of interferon- $\gamma$ in these cells. The peptide leucine-enkephalin stimulated the production of $\mathrm{T}$ helper cells and cytotoxic $\mathrm{T}$ cells (Sizemore et al., 1991).

Among peptides with antimicrobial activity described in the neuroendocrine system, those derived from chromogranins have been highlighted. They are members of the granin family, which are acidic proteins present in secretory vesicles in the endocrine and immune systems (Shooshtarizadeh et al., 2010). Chromogranins have shown multiple-biological activities including neuroendocrine activity, modulation of homeostatic processes such as regulation of calcium metabolism and glucose, gastrointestinal 
motility, nociception, strong activity in tissue repair, and inflammatory response mediation. More recently, peptides derived from chromogranins could act as defense agents during infections of bacteria and fungi. Moreover, chromogranin-derived peptides have shown activity in innate immunity, being able to activate polymorphonuclear neutrophils, mediate the monocyte chemotaxis, and induce microglial cell activation (Shooshtarizadeh et al., 2010). Peptides derived from chromogranins have shown special activity against pathogens commonly found in the skin, revealing that the expression of these peptides may be performed by keratinocytes. In these cells, chromogranin A fragments generated catestatin: a broad-spectrum antimicrobial peptide. These fragments induce monocyte chemotaxis and act on the production of cytokines and chemokines by mast cells (granulocytemacrophage colony-stimulating factor, monocyte chemotactic protein-1, macrophage inflammatory protein-1 $\alpha$, macrophage inflammatory protein- $1 \beta$, and chemokine - C-C motif - ligand 2, 3, and CCL2, CCL3, CCL4). Furthermore, it also stimulated keratinocyte interleukin-8 production through the activation of mitogen-activated protein kinases (Radek et al., 2008; Shooshtarizadeh et al., 2010). Other peptides derived from chromogranins, termed vasostatins, have shown deleterious activity against Grampositive bacteria, filamentous fungi, and yeasts (Dondossola et al., 2010). These studies have demonstrated that a neuroendocrine peptide may have antimicrobial activity against a wide variety of skin pathogens and may be up-regulated in the lesion. These data have demonstrated a direct link between the neuroendocrine and immune system (Shooshtarizadeh et al., 2010). Finally, the expression of catestatin in mice skin resulted in higher protection against infection and injury. Catestatin is a 21 -amino acid residue, which is made endogenously from the proteolytic cleavage of chromogranin A (Radek et al., 2008).

Studies have shown that members of the neuropeptide bombesin family, in addition to direct activity against microorganisms, mediate a variety of biological activities in the gastrointestinal tract and central nervous system (CNS) of mammals, including smooth muscle contraction, hormone secretion, cell proliferation stimulation, and central-homeostatic mechanism regulation ( $\mathrm{Su}$ et al., 2010). Another HDP family found in mammalian brains are hepcidins, which besides having direct antimicrobial activity, also reduce secretion of TNF- $\alpha$, IL- $1 \alpha$, IL- $1 \beta$, and IL- 6 by regulating the COX-2 gene and PDE4D by using mechanisms dependent on pERK1/2 in macrophage cells (Su et al., 2010). In this view, due to LPS stimulation, a significant increase in hepcidin mRNA expression was observed in cortex and substantia nigra. These findings suggest that the CNS can use many peptides as anti-infective and immunomodulatory agents by delivering them quickly and accurately to innervated sites, indicating a new dimension for an immunomodulatory role for neuropeptides in inflammatory and immune responses (El Karim et al., 2008).

\section{HOST-DEFENSE PEPTIDES: FUNDAMENTAL MOLECULES IN RESPONSE TO HUMAN MICROBIAL INFECTIONS}

HDPs are evolutionarily ancient molecules that reinforce the human innate immune system against microbial invasion (Nijnik et al., 2009). A constitutive HDP expression has been observed in phagocytic cells and in body tissues (Figure 3). This occurrence

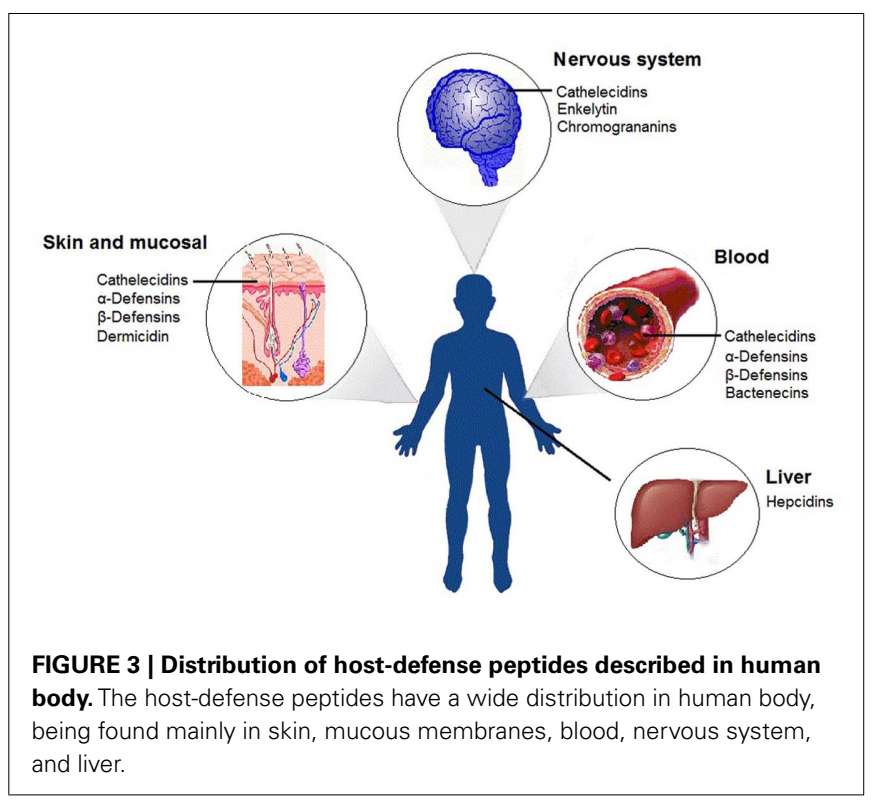

happens particularly at human interfaces between the environment and the host, such as skin and mucosal membranes (Hirsch et al., 2008). HDP synthesis and release are regulated by microbial stimuli, cytokines, neuroendocrine signals, and epigenetic regulation (Ganz, 2003).

Along these lines, intestinal mucosal pathologies, such as Crohn's disease and intestinal inflammation, result from the reduction of $\alpha$-defensin expression in the small intestine (Inaba et al., 2010). The protective role of $\alpha$-defensins against pathogenic bacteria in intestinal infections has been certified in $\alpha$ defensin-deficient mice, since mice became more susceptible to Salmonella typhimurium infections (Inaba et al., 2010). Moreover, hBD1 and hBD2 are important HDPs in gastric-intestinal mucosa. The expression of both peptides increased in the gastric antrum mucosa, which is commonly induced by gastritis caused via Helicobacter pylori (Bajaj-Elliott et al., 2002).

Regarding HDPs produced in human skin, patients with infectious cellulitis presented an increased expression of LL-37 and $\beta$-defensin in comparison with those normal skins (Stryjewski et al., 2007). This datum suggests that HDPs may provide additional protection against microbial dissemination, confining the focus of infectious cellulitis to a single location. However, patients with atopic dermatitis presented an absence or reduced expression of LL-37, hBD2, hBD3, and dermicidin (Bernard and Gallo, 2011). These findings suggest that patient susceptibility to atopic dermatitis in skin infections could be higher due to a significant increase in either bacterial colonization, fungal, or viral infections (Bernard and Gallo, 2011). Recent studies have detected high levels of human $\beta$-defensin, hBD2, hBD3, and psoriasin in cutaneous infections after skin surgery (Kesting et al., 2010). Expression of $\mathrm{hBD} 2-3$ is reduced in burn wounds, while the expression hBD1 is unchanged (Milner and Ortega, 1999). However, the skin's lower layers continue to express hBD1-3 after wound recovery, maintaining a barrier against infection and preventing burn sepsis (Poindexter et al., 2006). 
Sepsis is a major cause of mortality and high hospital costs and, despite the efforts that have been made by public health authorities in recent decades, the incidence of this syndrome continues to increase year after year due in particular to the increasing emergence of microorganisms resistant to the available antibiotics (Barnato et al., 2008). Several HDPs have been reported to modulate the host response to bacterial sepsis. LL-37 acted as a potent inflammation molecule mediator, protecting mice and rats from the lethal effects of endotoxemia and intra-abdominal sepsis. This protection occurs due to a reduction in the levels of TNF- $\alpha$ and LPS in plasma, which inhibit the activation of macrophages by LPS, lipoteichoic acid (LTA), and non-mannose-capped lipoarabinomannan, as well as regulating the expression of coding genes and receptors (CXCR-4, CCR2, and IL-8RB) of chemokines in macrophages (Torossian et al., 2007). The main mechanism of TNF- $\alpha$ expression inhibition by LL-37 in mice is believed to occur by the blocking of LBP-mediated transport of LPS in CD14 ${ }^{+}$ cells (Nagaoka et al., 2001). HDPs buforin II, indolicidin, and cecropin B have shown effectiveness in the treatment of rats with septic/endotoxic shock caused by multi-resistant Escherichia coli and LPS, significantly reducing the plasma levels of endotoxin and TNF- $\alpha$ when compared to animals treated with piperacillin (Vallespi et al., 2003). Limulus anti-LPS factor (LALF), a peptide isolated from the horseshoe crab, could increase the survival of mice after administration of a lethal $P$. aeruginosa dose. This activity may be correlated with a decreased TNF- $\alpha$ mRNA synthesis and elevation of systemic IL-2, IL-12, and IL-13 into animal spleen and livers (Vallespi et al., 2003). Mice with endotoxic shock derived from an LPS and treated with S-thanatin, an insect peptide, showed reduced levels of TNF- $\alpha$ accompanied by a significant increase (80\%) of animal survival (Wu et al., 2011a). In another study, animals infected with multi-resistant $P$. aeruginos $a$ and further treated with a single dose of tachyplesin III isolated from horseshoe crabs has shown reduced TNF- $\alpha$ levels in contrast to a clear survival increase (Cirioni et al., 2007). Treatment of amphibian source magainins (I, II, and III) in septic/endotoxic shock significantly reduced the concentrations of endotoxin and TNF- $\alpha$ in plasma rats, thus increasing host survival (Cirioni et al., 2002). These data suggest that peptides that could act against septic shock could be found at different sources and their activities are clearly related to TNF- $\alpha$ inhibition and endotoxin neutralization, which seem to be important mechanisms that increase the survival of infected animals.

\section{NOVEL AND CLASSICAL STRATEGIES FOR HDPs ISOLATION}

Currently, several limitations have driven the area in the development and production of HDP molecules away from natural peptides to the shorter and more stable synthetic forms. Libraries, synthetic strategies, and peptidomimetic technologies are being refined in order to overcome current limitations (Yeung et al., 2011).

Traditionally, since the beginning in 1928, with the discovery of lantibiotic Nisin produced by a Lactococcus lactis, until nearly the end of the twentieth century, the discovery and identification of peptide antimicrobial molecules from natural sources with pharmaceutical anti-infectious purposes have been carried out by conventional biochemical procedures. Both goals frequently started from an expected and confirmed biological activity: generally a direct inhibition of microbial growth of bacteria, virus, fungi, and parasites (using a medical concept of microbes). This primary evaluation of crude extracts was the starting point for combined steps of clarification, salt or acid precipitation, ultrafiltration, chromatographic purification, and the eventual available structural characterization. This approach, on the other hand, required an important volume of specimen, whole bodies or parts, to assure a significant level of antimicrobial activity. These procedures were achieved representing a real ecological challenge for the different life kingdoms if, finally, a large-scale pharmaceutical industry could be implemented for sustaining permanent production based on such an animal source (Bulet, 2008). Such natural sources were, in principle, associated with invertebrates, since HDPs are their major humoral tool to defeat a vast microbial challenge and must be effective in the absence of acquired immunity (Otero-Gonzalez et al., 2010). Today, multiple AMPs have been explored also for their immunomodulatory properties even when they are, in vivo, less potent for directly killing microbes than their conventional antibiotic counterparts (Lai and Gallo, 2009).

New trends in research are currently categorizing the discovery of new HDPs through the use of biological peptide libraries, thus providing a larger and more diverse quantity of molecules for evaluation. Such libraries based on phage (Pini et al., 2005), bacterial (Betscheider and Zangen, 2005), or ribosome display (Xie et al., 2006) are nevertheless time-consuming procedures and difficult to handle. In fact, a novel method for the identification of AMPs using a phage library and bacterial magnetic particles has been reported (Betscheider and Zangen, 2005; Pini et al., 2005). Using this library, six antibacterial peptides specifically active against $B$. subtilis have been identified. It was the first attempt that showed the functionality of a magnetic selection of HDPs targeting the bacterial inner membrane. Furthermore, these methodologies produce fusion instead of individual peptides and, additionally, only amino acids encoded in the genome can be used with a reasonable support of biological diversity. A clear advantage of these approaches is that peptides are biologically synthesized, avoiding the use of expensive chemicals and facilities (Mcphee et al., 2005). Furthermore, the advances in the genomic area including next generation sequencing and improvements in databank and bioinformatics tools have permitted the identification of many different compounds including HDPs. In a well-designed genetic approach reported in flatfish, the identification of active, novel antimicrobial molecules has been determined by screening both the genomic information and the mRNA transcripts from a number of different sequences encoding AMPs. Predictions of active peptide sequences from the genetic information were the starting point for the production of chemically synthesized peptides that have been tested for their cognate activities. A very active peptide was found to show inhibitory activity against a test panel of pathogens including antibiotic-resistant bacteria and fungi (Patrzykat et al., 2003).

As an attempt to expand the efficiency of discovering novel and effective HDPs, including unnatural HDPs, chemical peptide libraries are open to amino acids not encoded in the genome, Damino acids, and even non-canonical amino acids. Screening large numbers of peptides using a synthesis of peptide arrays on cellulose membranes (SPOT technology) provides an extraordinary 
tool for characterizing large quantities of peptides for a particular biological activity (Hilpert, 2010). This improved method using hydroxymethyl phenoxyacetic acid (HMPA) for 19 amino acids and 4-(4-hydroxymethyl-3-methoxyphenoxy)-butyric acid (HMPB) for proline, since acidic labile linkers in SPOT synthesis have been developed. Using this approach, reduced side-chain reactions, normally occurring during conventional alkaline peptide cleavage of cellulose membranes, was achieved. This method is suitable for synthesizing many thousands of different peptides subsequently used for direct multiple-biological assays (Ay et al., 2008).

Since the search for novel classes includes the purification process, the properties of target peptides such as hydrophobicity, cationicity, and small size have been broadly used in their purification. As follows, reversed-phase chromatography, ion exchange, and gel filtration are commonly included in the purification procedures for these molecules (Schroder, 2010). Although direct interaction of HDPs with different target molecules such as LPS (Gustafsson et al., 2010), lipid II (Schneider et al., 2010), and sphingolipid receptors are widely known (de Medeiros et al., 2010), affinity chromatography has not been widely used for their isolation. The use of this type of chromatography may improve the isolation of AMPs with desired affinities for biomolecules. For example, HDPs with the ability to bind LPS are very important in the treatment of sepsis, as previously described (Giuliani et al., 2010). However, the majority of molecules capable of inhibiting LPS have been synthesized on the basis of the Limulus antilipopolysaccharide factor (Andra et al., 2004). There is little doubt that the rational use of the LPS-affinity chromatography could enhance the number of natural HDPs with anti-LPS activity. In this case, affinity chromatography also acts as a screening procedure. In fact, it has isolated lipopolysaccharide-binding proteins from porcine milk and from the invertebrate hemolymph Tachypleus tridentatus using a similar chromatographic principle (Shahriar et al., 2006). Furthermore, HDPs are able to be induced, being another HDP property that could be exploited in their purification (Lavine et al., 2005). In fact, the microbial challenge test of different vertebrates and invertebrates permitted the isolation of augmented HDPs (Isobe et al., 2009). Thus, it could be possible to induce HDPs with a potent anti-proliferative activity against a particular group of pathogens (Lemaitre et al., 1997). The induction of these molecules may reveal basal HDPs and facilitate their purification by augmenting the concentration levels for further purification. Traditionally, once a peptide sequence had been identified and/or partially purified from a natural source, a structural approach had been applied with the aim to improve its antimicrobial activity and/or decrease its toxic or antigenic implications for experimental tests in animals or initial human trials. In this sense, amino acid substitutions based on the sequence data or on the three-dimensional structure such as the replacing of arginine residues with $\alpha$-amino-3-guanidino-propionic acid of the natural peptides may help to reduce serum AMPs degradation. The modified peptide stability was increased by nearly $80 \%$ without affecting the antimicrobial activity (Knappe et al., 2010). In a completely different but valid approach (based on the membrane-binding activity of most AMPs), cell membrane affinity chromatography has been reported to screen antibacterial peptide molecules from plant extracts. In this case, cell membrane affinity chromatography was useful for primary screening of cell membrane receptors according to its chromatographic retention. This constitutes one of the first reports on a high-throughput screening (HTS) of AMPs by such a principle (Xiao et al., 2011).

High-throughput screening is a well-established method in the bio-industry and is now used for basic and applied scientific research (Figure 4). It involves the screening of large biological and chemical libraries for activity against biological targets by automation, miniaturized assays, and large-scale data processing (Mayr and Bojanic, 2009). While HTS was initially applied to relatively non-complex simple assays concerning single molecular objectives or using affinity interactions relationships, HTS has also been applied to more integrated complex biological multicomponent systems, such as whole-cell-based tests. The intense need for novel and efficient antimicrobial molecules highlights the existence of multi-drug-resistant microorganisms, where multipletarget or cell-based assays are frequently desired, and thus is obliging researchers to reflect on multi-target, high-throughput technologies (Blondelle and Lohner, 2010). Clearly, an improved understanding of non-lytic modes of HDP interaction with target microbes will lead to the design and discovery of more effective antimicrobial molecules (Marcos and Gandía, 2009). In the pharmaceutical industry, HTS means challenging millions of molecules in massive automated applications. On the other hand, in a current academic laboratory, it may imply screening only a small quantity of peptides, mainly by conventional artisanal techniques. HDP activity may be best described by the concept of "interfacial activity" (Wimley, 2010). Structure-function relationships are infrequently utilized. The next challenge is not the generation of an extensive repertoire of molecules, but HTS employed to efficiently identify the active members from a massive source. In general, HTS could be divided into two categories: biological and nonbiological procedures (Rathinakumar and Wimley, 2010), which will be discussed next.

\section{IN VITRO AND IN SILICO BIOLOGICAL ASSAYS FOR THE FUNCTIONAL EVALUATION OF HDPS}

Broth dilution and agar diffusion methods, in which the activity of HDPs are directly estimated for the inhibition of microbial growth in a nutritive broth, could be in principle amended for HTS (Wiegand et al., 2008). Automated and massive variations of such procedures have been established in order to scale the number and diversity of HDPs to be verified. The use of luminescent bacteria for fast screening and characterization of short cationic AMPs synthetically immobilized in cellulose using peptide array technology has been developed (Hilpert et al., 2005). In this unusual approach, the authors used bacteria expressing the luciferase gene cassette (luxCDABE). Any synthetic peptide decreasing the energy level within the microbial cell will cause a quantifiable decrease in luminescence. The effectiveness of a tested molecule, at different concentrations, is reflected by the decreasing rate in luminescence. The assay is rapid and high-throughput and has shown significant correlation when compared with conventional suspension inhibitory culture assays performed with the same peptides synthesized by standard solid-phase peptide synthesis. Using this approach, 277 variants of the antimicrobial peptide 


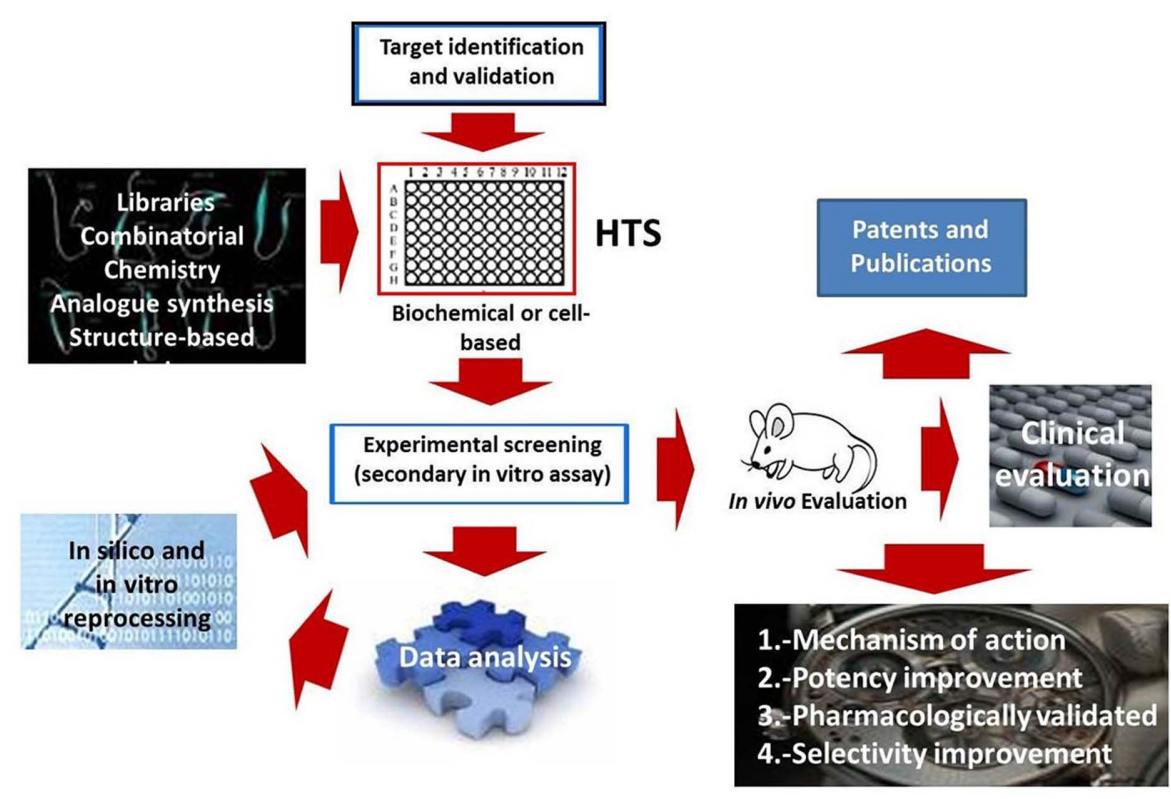

FIGURE 4 | A typical "end point" high-throughput screening flow for searching novel host-defense peptides.

Bac2A (a 12-mer linear variant of the HDP bactenecin) were studied. The antimicrobial activity of Bac2A derivatives ranged from superior to inactive compared to Bac2A (Hilpert et al., 2006). This technology allowed for a decreased amount of time required to convert leaded antimicrobial molecules into drugs.

In another interesting approach, a novel assay that had exploited fluorescence resonance energy transfer (FRET) was set up for antimicrobial peptide screening. It took advantage of changes in $\mathrm{pH}$ that occur in FRET efficiency due to the instability of increased yellow fluorescent protein against the stability of increased cyan fluorescent protein in a reduced-pH environment. Evaluation of antimicrobial activity was achieved through a difference of FRET efficiency between fusion molecules released from disrupted bacteria. It represented a clear example applicable to HTS of candidate peptide libraries (Kim and Cha, 2006). In this line of thought, a high-throughput method for screening cDNA libraries has been developed to detect possible AMPs. It was based on a fast dye inclusion assay for determining a bacterial viability loss. Colonies were grown on a membrane on a suitable medium until full colony development. The membrane containing the array of colonies is transferred onto an inductive medium containing a vital dye. Upon expression of any active peptides, the cell membrane becomes susceptible and permits dye infusion to induce visual identification of positive peptides (Loit et al., 2008). In this way, a random oligonucleotide library containing a potential pool of 100,000 peptides was screened. The authors found three novel antibacterial peptides. One of them has shown membrane disruption and bacterial aggregation activity (Loit et al., 2010). Unfortunately, these HTSs are not available yet for other HDP activities like immunomodulation or wounding repair. The development of techniques in these areas will boost the insertion of HDPs into the drug industry.
An early attempt for automating the screening of membranerelated AMPs was reported in which a colorimetric sensor by which particles composed of phospholipids and polymerized polydiacetylene lipids were shown to exhibit clearly visible color changes upon interactions with antimicrobial membrane peptides. The color changes in the system are due to a structural perturbation of the lipids after their interactions with AMPs. The assay was also valuable for detecting functionally related peptide analogs (Kolusheva et al., 2000). Alamethicin, gramicidin, and valinomycin have been investigated in such planar film systems (Volinskya et al., 2006). Otherwise, the in silico-based screening systems include computerized methods as well as simulation methods that mimic the interaction between peptides and membranes (Raventos et al., 2005). A mathematical model has been developed to predict, before synthesis, a peptide with an activity against $P$. aeruginosa (Jenssen et al., 2008). Using original descriptors for assessing the contact energy between spatially closed amino acids, as well as a set of inductive and conventional quantitative structure-activity relationship (QSAR) descriptors, it has been possible to model the antibacterial activity of peptides before the synthesis step. Cross-correlation and optimization of the selected descriptor values permitted these authors to build two models, using very limited number of peptides. Even when such models were significantly different in size, no significant difference was demonstrated in their predictive power, meaning that it was possible to use this tool to obtain useful and potent predictive models, even when using small sets of peptides with different structures. The development of biological assays in HTS has increased the number of known antimicrobial structures allowing the development of newer inductive QSAR descriptors, which in combination with more complex mathematical algorithms, improve the in silico identification of novel HDPs (Hilpert et al., 2008). Also, QSAR 
descriptors have been developed for predicting antimicrobial peptide toxicity against host cells (Langham et al., 2008). Additionally, recent advances in molecular dynamics simulations of AMPs and membrane mimics offer new data to help us to understand the mechanism of action of these molecules (Langham and Kaznessis, 2010).

In a recent chemical approach, novel cationic AMPs were proposed with a simple strategy using acid-amide substitution to add a net positive charge to natural non-antibacterial amino acid sequences showing structures that were different from the reported cationic AMPs. Alterations produced in membranes by these modified peptides were evaluated and conformational changes were estimated from far-ultraviolet circular dichroism spectra. These novel cationic AMPs showed sequences completely distant from any other AMPs described before, suggesting that such modified natural sequences could be an interesting source of novel frames for cationic AMPs (Ueno et al., 2011).

\section{LARGE-SCALE HDP PRODUCTION: OVERCOMING A MAIN PROBLEM}

Structural and functional features, as well as several other significant physiological characteristics of these molecules as described in this review, are reasons why HDPs have received much attention from the scientific community for the development of new pharmaceuticals. However, there are real barriers in developing and producing natural HDPs. The challenge begins with the understanding of the fundamental principles of action in HDPs, as well as their structure-function relationship and pharmaceutical potential (Wimley, 2010). The lack of this understanding has been one of the major reasons why the development of these peptides into new drugs has slowed. This is due to the fact that only a few heterologous systems are capable of yielding a sufficient amount (in the range of $\sim 50-690 \mathrm{mg} \mathrm{L}^{-1}$ ) of soluble and purified peptides in order to enlighten such extensive biological and structural questions (Xu et al., 2007; Li, 2009). Moreover, in order to accomplish pharmaceutical and biotechnological goals, it is necessary to produce these peptides in large-scale. This sort of production has been the biggest challenge in studies regarding screening, synthesis, and characterization of these molecules.

Despite two decades of continuous efforts, the limitation of small-scale production has impaired the successful use of HDPs in health care. For instance, only four peptides to date have reached global sales of over US\$ 1 billion as therapeutic drugs. These have been prescribed for treatments for multiple sclerosis as Glatiramer acetate (also known as Cop-1 or Copaxone; $\$ 3.8$ billion), for prostate cancer and breast cancer as leuprolide acetate (Lupron; $\$ 2.12$ billion) and goserelin acetate (Zoladex; $\$ 1.14$ billion), and for treatment of acromegaly and carcinoid syndrome as octreotide acetate (Sandostatin; $\$ 1.12$ billion; Peptide Therapeutics Foundation, 2010 Report Summary). Moreover, in the last 5 years, only one HDP, the human bactericidal/permeability-increasing protein $\mathrm{rBPI}_{23}$ (Neuprex - indicated for treatment of meningococcal sepsis) has been approved for marketing. Furthermore, only three HDPs have progressed to phase III of clinical-efficacy trials (Pexiganan, Iseganan, and Omiganan) and none of these have to date received FDA approval for clinical use (Hancock and Sahl, 2006; Yeung et al., 2011).
To change this scenario, current approaches need to be refined and new technologies are required to be employed in the development and production of HDPs. In order to recover and produce peptides, different methods can be employed such as the direct isolation from natural sources, chemical synthesis, or recombinant expression. The first strategy, despite extensive and efficient utilization at academic levels, it is extremely time-consuming and only low amounts of peptides are recovered from the host organism. This technique may even present environmental issues, especially for peptides isolated from species that occur in low numbers in nature (Li, 2011).

Chemical synthesis has been traditionally used to synthesize short and simple molecules and has allowed for the production of both natural and synthetic peptides (Zhou et al., 2010). However, it is tremendously costly and practically unfeasible for the synthesis of sequences larger than 15 residues of amino acids, running in the range of US\$ 100-600/g (Hancock and Sahl, 2006). Moreover, the cost may increase substantially due to difficulties that arise during synthesis of certain sequences such as those containing one or more disulfide bonds, or showing multiple post-translational modifications (Tay et al., 2011).

In view of the limits and inefficiencies of both methods described above, the most widely used method is the heterologous expression system. In the last few decades, various systems have been developed to reach a cost-effective and large-scale production of several proteins (Huber et al., 2005) and HDPs such as human defensins LL-37 and IDR-1 (Bommarius et al., 2010).

In most cases, the effectiveness of heterologous expression for the production of HDPs involves the fusion of carrier proteins containing an enzymatic or chemical cleavage site that allows the target peptide to be released. Some of these proteins act as stabilizing molecules due to their ability to neutralize the positive charge of the peptide, thus resulting in a non-toxic, efficient, and soluble expression of the target peptide (Rao et al., 2004). According to the Recombinantly produced AMPs Database (http://faculty.ist.unomaha.edu/; Li and Chen, 2008), the carrier protein most frequently used is the thioredoxin, representing more than $20 \%$ of all reported fusion proteins, followed by the use of GST (glutathione transferase- 12\%), PurF (amidophosphoribosyltransferase), and intein-mediated protein $(\sim 8 \%)$. The SUMO protein (small ubiquitin-related modifier) has been a promising carrier protein and has been shown to increase expression levels as well as the solubility of peptides (Malakhov et al., 2004; Bommarius et al., 2010).

The heterologous expression system may also be composed of one or more epitope tags (Rubio et al., 2005). These are short and hydrophilic peptide sequences recognized by specific antibodies, thus offering efficient detection. The most used epitope tags are HA (YPYDVPDYA), FLAG (DYKDDDDK), cMyc (EQKLISEEDL), and 6xHis (HHHHHH). Besides being used for subcellular location, their small size provides efficient affinity purification and is more likely to interfere less with the peptide of interest regarding its folding and function, when compared to larger carrier proteins (Earley et al., 2006).

Among the available commercial options of heterologous expression vectors, the most commonly used are those which belong to the pET and pQE series, developed by Novagen and 
Qiagen, respectively. These vectors have been largely used for expression of HDP derived from several organisms such as defensins from humans (e.g., $\alpha$-defensin 6$)$, bovine ( $\beta$-defensin 12) and defensin-like from fungus (plectasin; Wu et al., 2011b). In addition, new mutant strains of E. coli BL21 (DE3) have been developed to overcome the lethality caused by the expression of AMPs (Li et al., 2010).

Regarding the prokaryotic systems, E. coli is the most popular organism used to express recombinant proteins. Due to its features such as rapid growth rate, low cost, large availability for commercial expression vectors, and extensive knowledge about its genetics and physiology, E. coli has been applied to innumerable studies of synthesis and expression of AMPs and HDPs from different organisms (Canales et al., 2011) and has also been used in large-scale production of these peptides (Bommarius et al., 2010).

The limitation of the use of prokaryotic systems is to perform post-translational modifications required for stability and biological activity of certain peptides. To overcome this limitation, the use of eukaryotic systems is the appropriate approach. The yeast species Pichia pastoris and Saccharomyces cerevisiae represent the most common eukaryotic host system used for expression of heterologous proteins (Holz et al., 2002). The yeast P. pastoris has been used for expression of HDPs derived from humans and plants, although none have reported large-scale production (Yang et al., 2007). Naturally, the disadvantage in using these organisms is their innate sensitivity against antifungal peptides (Thevissen et al., 2007).

Plants have been a promising alternative for eukaryotic systems and numerous strategies have been developed to optimize these organisms to attend commercial production (Desai et al., 2010). The most common plant hosts are Nicotiana tabacum and Arabidopsis thaliana, which have been reported in expression of AMPs derived from plants such as LjAMP1, SmAMP1, and SmAMP2, which have activities against 15 plant pathogens, including those of economic concern. Furthermore, considering AMPs in plants act like HDPs, such as defensins, the expression of these molecules, either in plants or in bacteria, has been successfully achieved. However, there is no report in the literature regarding expression of HDPs from animal sources expressed in plants. Diverse studies have demonstrated viable possibilities of using plants for production of biotechnological products, contributing to the development of new heterologous expression systems to reach large-scale production (Pogue et al., 2010). Nevertheless, it should be emphasized that there needs to be advances in technology before these organisms can be chosen over bacteria as an expression system for recombinant HDPs.

The heterologous expression technologies overviewed here are of paramount concern regarding the production of natural or synthetic peptides in large-scale for therapeutic research and development. The development of new technology and the widespread acceptance of protein therapy as listed above will very likely increase the percentage of HDPs and AMPs as therapeutic candidates for pharmaceutical and biotechnological industries.

\section{CONCLUDING REMARKS}

As focused in this report, promiscuous AMPs and HDPs are evolutionarily primordial defensive molecules widely distributed in different kingdoms suggesting that they have played an essential role in the development of multicellular organisms. This central function comes from the fact that these promiscuous peptides present the ability to bind to different targets. In addition to the direct effects against microorganisms, HDPs also show the ability to act in the host organism, thus monopolizing the control of infections at higher levels. This ability involves basic functions of acquired immunity such as cytokine signal transduction, TLR interaction, and primeval immune memory, thus acting as effective immune modulators in mammals. Unfortunately, even though research on HDPs has lead to a better understanding of their functionality, the number of outbreaks is continuously increasing while few alternatives are currently available to combat these infections.

In order to control this increasing problem, novel strategies for treating infectious illnesses will be necessary, requiring additional manipulation of immune responses in order to intensely diminish the infectious agents and also avoid tissue wounds due to inflammation. The interchange ability between immunogenicity, danger signaling, and immune modulation of HDPs could act in synergy with the immunity normally offered by humans. In this view, normal patients subjected to resistant bacteria would clearly benefit. Moreover, patients with a compromised immune system subjected to severe opportunistic infections could also have the opportunity to improve their quality of life, reducing multiple infectious symptoms, e.g., fever, skin abscesses, chest pain, and shortness of breath.

Nevertheless, many problems must be solved for efficient HDP selection and production. Regarding the selection issue, novel compounds must be screened from different and unusual sources exploring different biomes and environments. The production problems must be solved by using novel technologies of chemical synthesis, and also novel strategies of heterologous production. An additional problem is the low stability of some peptides. This can be improved by several methods including the production of mutants and also the design of novel particles that could protect the peptide against host-hostile environments, providing an efficient delivery system. One must ask whether peptides are capable of correctly modulating the host immune system. If not, the collateral effects will be worse than the proper infection. This does not seem to be the case, at least when considering the many trials using animal models. Nevertheless, several clinical trials using human beings must be performed in order to provide security for all patients. The use of the AMPs or HDPs is inevitable and extremely desirable, but more studies must be performed in order to really understand the mechanisms of action of such molecules. Indeed, researchers must use all the available technology possible including proteomics, genomics, transcriptomics, nanobiotechnology, and many others in order to reduce the detrimental effects on the population. The infectious storm is upon the human species and the best that we can do is be prepared for it by constructing and producing the best compounds possible.

\section{ACKNOWLEDGMENTS}

This work was supported by CAPES, CNPq, FAPDF, and UCB. 


\section{REFERENCES}

Andra, J., Lamata, M., Martinez De, T. G., Bartels, R., Koch, M. H., and Brandenburg, K. (2004). Cyclic antimicrobial peptides based on Limulus anti-lipopolysaccharide factor for neutralization of lipopolysaccharide. Biochem. Pharmacol. 68, 1297-1307.

Arias, C. A., and Murray, B. E. (2009). Antibiotic-resistant bugs in the 21st century - a clinical super-challenge. N. Engl. J. Med. 360, 439-443.

Auvynet, C., and Rosenstein, Y. (2009). Multifunctional host defense peptides: antimicrobial peptides, the small yet big players in innate and adaptive immunity. FEBS J. 276, 6497-6508.

Ay, B., Landgrafa, K., Streitza, M., Fuhrmanna, S., Volkmera, R., and Boisguerin, P. (2008). Using hydroxymethyl phenoxy derivates with the SPOT technology to generate peptides with authentic C-termini. Bioorg. Med. Chem. 18, 4038-4043.

Bajaj-Elliott, M., Fedeli, P., Smith, G. V., Domizio, P., Maher, L., Ali, R. S., Quinn, A. G., and Farthing, M. J. (2002). Modulation of host antimicrobial peptide (beta-defensins 1 and 2) expression during gastritis. Gut 51, 356-361.

Barnato, A. E., Alexander, S. L., LindeZwirble, W. T., and Angus, D. C. (2008). Racial variation in the incidence, care, and outcomes of severe sepsis: analysis of population, patient, and hospital characteristics. Am. J. Respir. Crit. Care Med. 177, 279-284.

Benko-Iseppon, A. M., Galdino, S. L., Calsa, T. Jr., Kido, E. A., Tossi, A., Belarmino, L. C., and Crovella, S. (2010). Overview on plant antimicrobial peptides. Curr. Protein Pept. Sci. 11, 181-188.

Bernard, J. J., and Gallo, R. L. (2011). Protecting the boundary: the sentinel role of host defense peptides in the skin. Cell. Mol. Life. Sci. 68, 2189-2199.

Berrocal-Lobo, M., Molina, A., Rodriguez-Palenzuela, P., GarciaOlmedo, F., and Rivas, L. (2009). Leishmania donovani: thionins, plant antimicrobial peptides with leishmanicidal activity. Exp. Parasitol. 122, 247-249.

Betscheider, J. J., and Zangen, D. D. (2005). Bacterial surface display library screening by target enzyme labeling: identification of new human cathepsin $\mathrm{G}$ inhibitors. Anal. Biochem. 346, 258-267.

Biragyn, A., Ruffini, P. A., Leifer, C. A., Klyushnenkova, E., Shakhov, A., Chertov, O., Shirakawa, A. K., Farber,
J. M., Segal, D. M., Oppenheim, J. J., and Kwak, L. W. (2002). Toll-like receptor 4-dependent activation of dendritic cells by beta-defensin 2 . Science 298, 1025-1029.

Blondelle, S. E., and Lohner, K. (2010). Optimization and highthroughput screening of antimicrobial peptides. Curr. Pharm. Des. 16, 3204-3211.

Bommarius, B., Jenssen, H., Elliott, M., Kindrachuk, J., Pasupuleti, M., Gieren, H., Jaeger, K. E., Hancock, R. E., and Kalman, D. (2010). Costeffective expression and purification of antimicrobial and host defense peptides in Escherichia coli. Peptides 31, 1957-1965.

Bowdish, D. M., Davidson, D. J., Scott, M. G., and Hancock, R. E. (2005). Immunomodulatory activities of small host defense peptides. Antimicrob. Agents Chemother. 49, 1727-1732.

Braff, M. H., Hawkins, M. A., Di Nardo, A., Lopez-Garcia, B., Howell, M. D., Wong, C., Lin, K., Streib, J. E., Dorschner, R., Leung, D. Y., and Gallo, R. L. (2005). Structure-function relationships among human cathelicidin peptides: dissociation of antimicrobial properties from host immunostimulatory activities. J. Immunol. 174, 4271-4278.

Bulet, P. (2008). Strategies for the discovery, isolation, and characterization of natural bioactive peptides from the immune system of invertebrates. Methods Mol. Biol. 494, 9-29.

Canales, J., Avila, C., and Canovas, F. M. (2011). A maritime pine antimicrobial peptide involved in ammonium nutrition. Plant Cell Environ. 34, 1443-1453.

Carvalho Ade, O., and Gomes, V. M. (2009). Plant defensins - prospects for the biological functions and biotechnological properties. Peptides 30, 1007-1020.

Chen, X., Niyonsaba, F., Ushio, H., Hara, M., Yokoi, H., Matsumoto, K., Saito, H., Nagaoka, I., Ikeda, S., Okumura, K., and Ogawa, H. (2007). Antimicrobial peptides human betadefensin (hBD)-3 and hBD-4 activate mast cells and increase skin vascular permeability. Eur. J. Immunol. 37, 434-444.

Chen, X. Y., and Kim, J. Y. (2009). Callose synthesis in higher plants. Plant Signal. Behav. 4, 489-492.

Cirioni, O., Ghiselli, R., Silvestri, C., Kamysz, W., Orlando, F., Mocchegiani, F., Di Matteo, F., Riva, A., Lukasiak, J., Scalise, G., Saba, V., and Giacometti, A. (2007).
Efficacy of tachyplesin III, colistin, and imipenem against a multiresistant Pseudomonas aeruginosa strain. Antimicrob. Agents Chemother. 51, 2005-2010.

Cirioni, O., Giacometti, A., Ghiselli, R., Mocchegiani, F., Fineo, A., Orlando, F., Del Prete, M. S., Rocchi, M., Saba, V., and Scalise, G. (2002). Single-dose intraperitoneal magainins improve survival in a gram-negative-pathogen septic shock rat model. Antimicrob. Agents Chemother. 46, 101-104.

Colgrave, M. L., Kotze, A. C., Huang, Y. H., O'Grady, J., Simonsen, S. M., and Craik, D. J. (2008). Cyclotides: natural, circular plant peptides that possess significant activity against gastrointestinal nematode parasites of sheep. Biochemistry 47, 5581-5589.

Colgrave, M. L., Kotze, A. C., Kopp, S., McCarthy, J. S., Coleman, G. T., and Craik, D. J. (2009). Anthelmintic activity of cyclotides: in vitro studies with canine and human hookworms. Acta Trop 109, 163-166.

Craik, D. J. (2010). Discovery and applications of the plant cyclotides. Toxicon 56, 1092-1102.

de Medeiros, L. N., Angeli, R., Sarzedas, C. G., Barreto-Bergter, E., Valente, A. P., Kurtenbach, E., and Almeida, F. C. (2010). Backbone dynamics of the antifungal Psd 1 pea defensin and its correlation with membrane interaction by NMR spectroscopy. Biochim. Biophys. Acta 1798, 105-113.

Desai, P. N., Shrivastava, N., and Padh, H. (2010). Production of heterologous proteins in plants: strategies for optimal expression. Biotechnol. Adv. 28, 427-435.

Dondossola, E., Gasparri, A., Bachi, A., Longhi, R., Metz-Boutigue, M. H., Tota, B., Helle, K. B., Curnis, F., and Corti, A. (2010). Role of vasostatin$1 \mathrm{C}$-terminal region in fibroblast cell adhesion. Cell. Mol. Life. Sci. 67, 2107-2118.

Earley, K. W., Haag, J. R., Pontes, O., Opper, K., Juehne, T., Song, K., and Pikaard, C. S. (2006). Gatewaycompatible vectors for plant functional genomics and proteomics. Plant J. 45, 616-629.

El Karim, I. A., Linden, G. J., Orr, D. F. and Lundy, F. T. (2008). Antimicrobial activity of neuropeptides against a range of micro-organisms from skin, oral, respiratory and gastrointestinal tract sites. J. Neuroimmunol. 200, 11-16.

Felizmenio-Quimio, M. E., Daly, N. L., and Craik, D. J. (2001). Circular proteins in plants: solution structure of a novel macrocyclic trypsin inhibitor from Momordica cochinchinensis. J. Biol. Chem. 276, 22875-22882.

Fleming, A. (1929). On the antibacterial action of cultures of a penicillium, with special reference to their use in the isolation of $B$. influenzae. 1929. Bull. World Health Organ. 79, 780-790.

Franco, O. L. (2011). Peptide promiscuity: an evolutionary concept for plant defense. FEBS Lett. 585, 995-1000.

Ganz, T. (2003). Defensins: antimicrobial peptides of innate immunity. Nat. Rev. Immunol. 3, 710-720.

Garcia-Olmedo, F., Molina, A., Alamillo, J. M., and Rodriguez-Palenzuela, P. (1998). Plant defense peptides. Biopolymers 47, 479-491.

Gerlach, S. L., Rathinakumar, R., Chakravarty, G., Goransson, U., Wimley, W. C., Darwin, S. P., and Mondal, D. (2010). Anticancer and chemosensitizing abilities of cycloviolacin 02 from Viola odorata and psyle cyclotides from Psychotria leptothyrsa. Biopolymers 94, 617-625.

Giuliani, A., Pirri, G., and Rinaldi, A. C. (2010). Antimicrobial peptides: the LPS connection. Methods Mol. Biol. 618, 137-154.

Goumon, Y., Strub, J. M., Moniatte, M., Nullans, G., Poteur, L., Hubert, P., Van Dorsselaer, A. Aunis, D., and Metz-Boutigue, M. H. (1996). The C-terminal bisphosphorylated proenkephalinA-(209-237)-peptide from adrenal medullary chromaffin granules possesses antibacterial activity. Eur. J. Biochem. 235, 516-525.

Gran, L. (1973). On the effect of a polypeptide isolated from "KalataKalata" (Oldenlandia affinis DC) on the oestrogen dominated uterus. Acta Pharmacol. Toxicol. 33, 400-408.

Gustafson, K. R., Sowder, R. C., Henderson, L. E., Parsons, I. C., Kashman, Y., Cardellina, J. H., Mcmahon, J. B., Buckheit, R. W., Pannell, L. K., and Boyd, M. R. (1994). Circulins A and B. Novel human immunodeficiency virus (HIV)-inhibitory macrocyclic peptides from the tropical tree Chassalia parvifolia. J. Am. Chem. Soc. 116, 9337-9338.

Gustafsson, A., Olin, A. I., and Ljunggren, L. (2010). LPS interactions with immobilized and soluble antimicrobial peptides. Scand. $J$. Clin. Lab. Invest. 70, 194-200.

Hancock, R. E., Brown, K. L., and Mookherjee, N. (2006). Host defence peptides from invertebrates - emerging antimicrobial strategies. Immunobiology 211, 315-322. 
Hancock, R. E., and Chapple, D. S. (1999). Peptide antibiotics. Antimicrob. Agents Chemother. 43, 1317-1323.

Hancock, R. E., and Sahl, H. G. (2006). Antimicrobial and hostdefense peptides as new antiinfective therapeutic strategies. Nat. Biotechnol. 24, 1551-1557.

Hématy, K., Cherk, C., and Somerville, S. (2009). Host-pathogen warfare at the plant cell wall. Curr. Opin. Plant Biol. 12, 406-413.

Hilpert, K. (2010). High-throughput screening for antimicrobial peptides using the SPOT technique. Methods Mol. Biol. 618, 125-133.

Hilpert, K., Elliott, M. R., VolkmerEngert, R., Henklein, P., Donini, O., Zhou, Q., Winkler, D. F., and Hancock, R. E. (2006). Sequence requirements and an optimization strategy for short antimicrobial peptides. Chem. Biol. 13, 1101-1107.

Hilpert, K., Fjell, C. D., and Cherkasov, A. (2008). Short linear cationic antimicrobial peptides: screening, optimizing, and prediction. Methods Mol. Biol. 494, 127-159.

Hilpert, K., Volkmer-Engert, R., Walter, T., and Hancock, R. E. (2005). High-throughput generation of small antibacterial peptides with improved activity. Nat. Biotechnol. 23, 1008-1012.

Hirsch, T., Metzig, M., Niederbichler, A., Steinau, H. U., Eriksson, E., and Steinstraesser, L. (2008). Role of host defense peptides of the innate immune response in sepsis. Shock $30,117-126$.

Holz, C., Hesse, O., Bolotina, N., Stahl, U., and Lang, C. (2002). A micro-scale process for highthroughput expression of cDNAs in the yeast Saccharomyces cerevisiae. Protein Expr. Purif. 25, 372-378.

Huang, Y., Huang, J., and Chen, Y. (2010). Alpha-helical cationic antimicrobial peptides: relationships of structure and function. Protein Cell 1, 143-152.

Huber, D., Boyd, D., Xia, Y., Olma, M. H., Gerstein, M., and Beckwith, J. (2005). Use of thioredoxin as a reporter to identify a subset of Escherichia coli signal sequences that promote signal recognition particle-dependent translocation. $J$. Bacteriol. 187, 2983-2991.

Inaba, Y., Ashida, T., Ito, T., Ishikawa, C., Tanabe, H., Maemoto, A., Watari, J., Ayabe, T., Mizukami, Y., Fujiya, M., and Kohgo, Y. (2010). Expression of the antimicrobial peptide alpha-defensin/cryptdins in intestinal crypts decreases at the initial phase of intestinal inflammation in a model of inflammatory bowel disease, IL-10-deficient mice. Inflamm. Bowel Dis. 16, 1488-1495.

Isobe, N., Morimoto, K., Nakamura, J., Yamasaki, A., and Yoshimura, Y. (2009). Intramammary challenge of lipopolysaccharide stimulates secretion of lingual antimicrobial peptide into milk of dairy cows. J. Dairy Sci. 92, 6046-6051.

Jenssen, H., Fjell, C. D., Cherkasov, A., and Hancock, R. E. (2008). QSAR modeling and computeraided design of antimicrobial peptides. J. Pept. Sci. 14, 110-114.

Kamphuis, S., Eriksson, F., Kavelaars, A., Zijlstra, J., Van De Pol, M., Kuis, W., and Heijnen, C. J. (1998). Role of endogenous pro-enkephalin Aderived peptides in human $\mathrm{T}$ cell proliferation and monocyte IL-6 production. J. Neuroimmunol. 84, 53-60.

Kesting, M. R., Stoeckelhuber, M., Holzle, F., Mucke, T., Neumann, K., Woermann, K., Jacobsen, F., Steinstraesser, L., Wolff, K. D., Loeffelbein, D. J., and Rohleder, N. H. (2010). Expression of antimicrobial peptides in cutaneous infections after skin surgery. Br. J. Dermatol. 163, 121-127.

Kim, Y. S., and Cha, H. J. (2006). High-throughput and facile assay of antimicrobial peptides using $\mathrm{pH}$ controlled fluorescence resonance energy transfer. Antimicrob. Agents Chemother. 50, 3330-3335.

Knappe, D., Henklein, P., Hoffmann, R., and Hilpert, K. (2010). Easy strategy to protect antimicrobial peptides from fast degradation in serum. Antimicrob. Agents Chemother. 54, 4003-4005.

Kolusheva, S., Boyer, L., and Jelinek, R. (2000). A colorimetric assay for rapid screening of antimicrobial peptides. Nat. Biotechnol. 18, 225-227.

Lai, Y., and Gallo, R. L. (2009). AMPed up immunity: how antimicrobial peptides have multiple roles in immune defense. Trends Immunol. $30,131-141$.

Langham, A., and Kaznessis, Y. N. (2010). Molecular simulations of antimicrobial peptides. Methods Mol. Biol. 618, 267-285.

Langham, A. A., Khandelia, H., Schuster, B., Waring, A. J., Lehrer, R. I., and Kaznessis, Y. N. (2008). Correlation between simulated physicochemical properties and hemolycity of protegrin-like antimicrobial peptides: predicting experimental toxicity. Peptides 29, 1085-1093.

Lavine, M. D., Chen, G., and Strand, M. R. (2005). Immune challenge differentially affects transcript abundance of three antimicrobial peptides in hemocytes from the moth Pseudoplusia includens. Insect Biochem. Mol. Biol. 35, 1335-1346.

Lemaitre, B., Reichhart, J. M., and Hoffmann, J. A. (1997). Drosophila host defense: differential induction of antimicrobial peptide genes after infection by various classes of microorganisms. Proc. Natl. Acad. Sci. U.S.A. 94, 14614-14619.

Li, C., Blencke, H. M., Paulsen, V., Haug, T., and Stensvag, K. (2010). Powerful workhorses for antimicrobial peptide expression and characterization. Bioeng. Bugs 1, 217-220.

Li, Y. (2009). Carrier proteins for fusion expression of antimicrobial peptides in Escherichia coli. Biotechnol. Appl. Biochem. 54, 1-9.

Li, Y. (2011). Recombinant production of antimicrobial peptides in Escherichia coli: a review. Protein Expr. Purif. 80, 260-267.

Li, Y., and Chen, Z. (2008). RAPD a database of recombinantlyproduced antimicrobial peptides. FEMS Microbiol. Lett. 289, 126-129.

Lin, P., Wong, J. H., and Ng, T. B. (2010). A defensin with highly potent antipathogenic activities from the seeds of purple pole bean. Biosci. Rep. 30, 101-109.

Loit, E., Hincke, M. T., and Altosaar, I. (2010). Synthetic antimicrobial peptide L8 (MHLHKTSRVTLYLL) has membrane permeabilisation and bacterial aggregation activity. Int. J. Antimicrob. Agents 35, 410-411.

Loit, E., Wu, K., Cheng, X., Hincke, M. T., and Altosaar, I. (2008). Functional whole-colony screening method to identify antimicrobial peptides. J. Microbiol. Methods 75, 425-431.

Ma, D. Z., Wang, H. X., and Ng, T. B. (2009). A peptide with potent antifungal and antiproliferative activities from Nepalese large red beans. Peptides 30, 2089-2094.

Malakhov, M. P., Mattern, M. R., Malakhova, O. A., Drinker, M., Weeks, S. D., and Butt, T. R. (2004). SUMO fusions and SUMO-specific protease for efficient expression and purification of proteins. J. Struct. Funct. Genomics 5, 75-86.

Marcos, J. F., and Gandía, M. (2009). Antimicrobial peptides: to membranes and beyond. Expert Opin. Drug Discov. 4, 659-671.

Matsuzaki, K. (1999). Why and how are peptide-lipid interactions utilized for self-defense? Magainins and tachyplesins as archetypes. Biochim. Biophys. Acta 1462, 1-10.
Mayr, L. M., and Bojanic, D. (2009). Novel trends in high-throughput screening. Curr. Opin. Pharmacol. 9, 580-588.

Mcphee, J. B., Scott, M. G., and Hancock, R. E. (2005). Design of host defence peptides for antimicrobial and immunity enhancing activities. Comb. Chem. High Throughput Screen. 8, 257-272.

Milner, S. M., and Ortega, M. R. (1999). Reduced antimicrobial peptide expression in human burn wounds. Burns 25, 411-413.

Mookherjee, N., Brown, K. L., Bowdish, D. M., Doria, S., Falsafi, R., Hokamp K., Roche, F. M., Mu, R., Doho, G. H., Pistolic, J., Powers, J. P., Bryan, J., Brinkman, F. S., and Hancock, R. E. (2006). Modulation of the TLRmediated inflammatory response by the endogenous human host defense peptide LL-37. J. Immunol. 176, 2455-2464

Mur, L. A. J., Kenton, P., Lloyd, A. J., Ougham, H., and Prats, E. (2008). The hypersensitive response; the centenary is upon us but how much do we know? J. Exp. Bot. 59, 501-520.

Nagaoka, I., Hirota, S., Niyonsaba, F., Hirata, M., Adachi, Y., Tamura, H., and Heumann, D. (2001). Cathelicidin family of antibacterial peptides CAP18 and CAP11 inhibit the expression of TNF-alpha by blocking the binding of LPS to CD14(+) cells. J. Immunol. 167, 3329-3338.

Nicolas, P. (2009). Multifunctional host defense peptides: intracellulartargeting antimicrobial peptides. FEBS J. 276, 6483-6496.

Nijnik, A., Pistolic, J., Wyatt, A., Tam, S., and Hancock, R. E. (2009). Human cathelicidin peptide LL-37 modulates the effects of IFN-gamma on APCs. J. Immunol. 183, 5788-5798.

Niyonsaba, F., Someya, A., Hirata, M., Ogawa, H., and Nagaoka, I. (2001). Evaluation of the effects of peptide antibiotics human beta-defensins1/-2 and LL-37 on histamine release and prostaglandin $\mathrm{D}(2)$ production from mast cells. Eur. J. Immunol. 31 , 1066-1075.

Niyonsaba, F., Suzuki, A., Ushio, H., Nagaoka, I., Ogawa, H., and Okumura, K. (2009). The human antimicrobial peptide dermcidin activates normal human keratinocytes. $B r . J$. Dermatol. 160, 243-249.

Otero-Gonzalez, A. J., Magalhaes, B. S., Garcia-Villarino, M., LopezAbarrategui, C., Sousa, D. A., Dias, S. C., and Franco, O. L. (2010). Antimicrobial peptides from marine invertebrates as a new frontier for microbial infection control. FASEB J. 24, 1320-1334. 
Padovan, L., Scocchi, M., and Tossi, A. (2010). Structural aspects of plant antimicrobial peptides. Curr. Protein Pept. Sci. 11, 210-219.

Patrzykat, A., Gallant, J. W., Seo, J. K., Pytyck, J., and Douglas, S. E. (2003). Novel antimicrobial peptides derived from flatfish genes. Antimicrob. Agents Chemother. 47, 2464-2470.

Perregaux, D. G., Bhavsar, K., Contillo, L., Shi, J., and Gabel, C. A. (2002). Antimicrobial peptides initiate IL-1 beta posttranslational processing: a novel role beyond innate immunity. J. Immunol. 168, 3024-3032.

Peters, B. M., Shirtliff, M. E., and Jabra-Rizk, M. A. (2010). Antimicrobial peptides: primeval molecules or future drugs? PLoS Pathog. 6, el001067. doi:10.1371/journal.ppat.1001067

Pini, A., Giuliani, A., Falciani, C., Runci, Y., Ricci, C., Lelli, B., Malossi, M., Neri, P., Rossolini, G. M., and Bracci, L. (2005). Antimicrobial activity of novel dendrimeric peptides obtained by phage display selection and rational modification. Antimicrob. Agents Chemother. 49, 2665-2672.

Pogue, G. P., Vojdani, F., Palmer, K. E., Hiatt, E., Hume, S., Phelps, J., Long, L., Bohorova, N., Kim, D., Pauly, M., Velasco, J., Whaley, K., Zeitlin, L., Garger, S. J., White, E., Bai, Y., Haydon, H., and Bratcher, B. (2010). Production of pharmaceutical-grade recombinant aprotinin and a monoclonal antibody product using plant-based transient expression systems. Plant Biotechnol. J. 8, 638-654.

Poindexter, B. J., Bhat, S., Buja, L. M., Bick, R. J., and Milner, S. M. (2006). Localization of antimicrobial peptides in normal and burned skin. Burns 32, 402-407.

Radek, K. A., Lopez-Garcia, B., Hupe, M., Niesman, I. R., Elias, P. M., Taupenot, L., Mahata, S. K., O'Connor, D. T., and Gallo, R. L. (2008). The neuroendocrine peptide catestatin is a cutaneous antimicrobial and induced in the skin after injury. $J$. Invest. Dermatol. 128, 1525-1534.

Rao, X. C., Li, S., Hu, J. C., Jin, X. L., Hu, X. M., Huang, J. J., Chen, Z. J., Zhu, J. M., and Hu, F. Q. (2004). A novel carrier molecule for high-level expression of peptide antibiotics in Escherichia coli. Protein Expr. Purif. 36, 11-18.

Rathinakumar, R., and Wimley, W. C. (2010). High-throughput discovery of broad-spectrum peptide antibiotics. FASEB J. 24, 3232-3238.

Raventos, D., Taboureau, O., Mygind, P. H., Nielsen, J. D., Sonksen, C. P., and
Kristensen, H. H. (2005). Improving on nature's defenses: optimization \& high throughput screening of antimicrobial peptides. Comb. Chem. High Throughput Screen. 8, 219-233.

Rubio, V., Shen, Y., Saijo, Y., Liu, Y., Gusmaroli, G., Dinesh-Kumar, S. P., and Deng, X. W. (2005). An alternative tandem affinity purification strategy applied to Arabidopsis protein complex isolation. Plant J. 41, 767-778.

Schneider, T., Kruse, T., Wimmer, R., Wiedemann, I., Sass, V., Pag, U., Jansen, A., Nielsen, A. K., Mygind, P. H., Raventos, D. S., Neve, S., Ravn, B., Bonvin, A. M., De, M. L., Andersen, A. S., Gammelgaard, L. K., Sahl, H. G., and Kristensen, H. H. (2010). Plectasin, a fungal defensin, targets the bacterial cell wall precursor lipid II. Science 328, 1168-1172.

Schroder, J. M. (2010). Purification of antimicrobial peptides from human skin. Methods Mol. Biol. 618, 15-30.

Sels, J., Mathys, J., De Coninck, B. M., Cammue, B. P., and De Bolle, M. F. (2008). Plant pathogenesis-related (PR) proteins: a focus on PR peptides. Plant Physiol. Biochem. 46, 941-950.

Shahriar, F., Gordon, J. R., and Simko, E. (2006). Identification of lipopolysaccharide-binding proteins in porcine milk. Can. J. Vet. Res. 70, 243-250.

Shan, F., Xia, Y., Wang, N., Meng, J., Lu, C., Meng, Y., and Plotnikoff, N. P. (2011). Functional modulation of the pathway between dendritic cells (DCs) and CD4+ T cells by the neuropeptide: methionine enkephalin (MENK). Peptides 32, 929-937.

Shooshtarizadeh, P., Zhang, D., Chich, J. F., Gasnier, C., Schneider, F., Haikel, Y., Aunis, D., and MetzBoutigue, M. H. (2010). The antimicrobial peptides derived from chromogranin/secretogranin family, new actors of innate immunity. Regul. Pept. 165, 102-110.

Sizemore, R. C., Dienglewicz, R. L., Pecunia, E., and Gottlieb, A. A. (1991). Modulation of concanavalin A-induced, antigen-nonspecific regulatory cell activity by leuenkephalin and related peptides. Clin. Immunol. Immunopathol. 60, 310-318.

Stryjewski, M. E., Hall, R. P., Chu, V. H., Kanafani, Z. A., O’Riordan, W. D., Weinstock, M. S., Stienecker, R. S., Streilein, R., Dorschner, R. A., Fowler, V. G. Jr., Corey, G. R., and Gallo, R. L. (2007). Expression of antimicrobial peptides in the normal and involved skin of patients with infective cellulitis. J. Infect. Dis. 196, 1425-1430.

Su, Y., Zhang, K., and Schluesener, H. J. (2010). Antimicrobial peptides in the brain. Arch. Immunol. Ther. Exp. (Warsz.) 58, 365-377.

Tay, D. K., Rajagopalan, G., Li, X., Chen, Y., Lua, L. H., and Leong, S. S. (2011). A new bioproduction route for a novel antimicrobial peptide. Biotechnol. Bioeng. 108, 572-581.

Thevissen, K., Kristensen, H. H. Thomma, B. P., Cammue, B. P., and Francois, I. E. (2007). Therapeutic potential of antifungal plant and insect defensins. Drug Discov. Today 12, 966-971.

Torossian, A., Gurschi, E., Bals, R., Vassiliou, T., Wulf, H. F., and Bauhofer, A. (2007). Effects of the antimicrobial peptide LL-37 and hyperthermic preconditioning in septic rats. Anesthesiology 107, 437-441.

Ueno, S., Minaba, S., Nishiuchi, Y., Taichi, M., Tamada, Y., Yamazaki, T., and Kato, Y. (2011). Generation of novel cationic antimicrobial peptides from natural nonantimicrobial sequences by acid-amide substitution. Ann. Clin. Microbiol. Antimicrob. 10, 11-14.

Vallespi, M. G., Alvarez-Obregon, J. C. Rodriguez-Alonso, I., Montero, T. Garay, H., Reyes, O., and Arana, M. J. (2003). A Limulus anti-LPS factorderived peptide modulates cytokine gene expression and promotes resolution of bacterial acute infection in mice. Int. Immunopharmacol. 3, 247-256.

Volinskya, R., Kolusheva, S., Berman, A., and Jelineka, R. (2006). Investigations of antimicrobial peptides in planar film systems. Biochim. Biophys. Acta 1758, 1393-1407.

Wiegand, I., Hilpert, K., and Hancock, R. E. (2008). Agar and broth dilution methods to determine the minimal inhibitory concentration (MIC) of antimicrobial substances. Nat. Protoc. 3, 163-175.

Wimley, W. C. (2010). Describing the mechanism of antimicrobial Peptide action with the interfacial activity model. ACS Chem. Biol. 5, 905-917.

Witherup, K. M., Bogusky, M. J., Anderson, P. S., Ramjit, H., Ransom, R. W., Wood, T., and Sardana, M. (1994). Cyclopsychotride A, a biologically active, 31-residue cyclic peptide isolated from Psychotria longipes. J. Nat. Prod. 57, 1619-1625.

Wong, J. H., and Ng, T. B. (2005). Lunatusin, a trypsin-stable antimicrobial peptide from lima beans (Phaseolus lunatus L.). Peptides 26, 2086-2092.

Wong, J. H., and Ng, T. B. (2006). Limenin, a defensin-like peptide with multiple exploitable activities from shelf beans. J. Pept. Sci. 12, 341-346.

Wu, G., Li, X., Deng, X., Fan, X., Wang, S., Shen, Z., and Xi, T. (2011a). Protective effects of antimicrobial peptide S-thanatin against endotoxic shock in mice introduced by LPS. Peptides 32, 353-357.

Wu, J., Wang, C., He, H., Hu, G., Yang, H., Gao, Y., and Zhong, J. (2011b). Molecular analysis and recombinant expression of bovine neutrophil beta-defensin 12 and its antimicrobial activity. Mol. Biol. Rep. 38, 429-436.

Xiao, J., Zhang, H., Niu, L., and Wang, X. (2011). Efficient screening of a novel antimicrobial peptide from Jatropha curcas by cell membrane affinity chromatography. J. Agric. Food Chem. 59, 1145-1151.

Xie, Q., Matsunaga, S., Wen, Z., Niimi, S., Kumano, M., Sakakibara, Y., and Machida, S. (2006). In vitro system for high-throughput screening of random peptide libraries for antimicrobial peptides that recognize bacterial membranes. J. Pept. Sci. 12, 643-652.

Xu, X., Jin, F., Yu, X., Ren, S., Hu, J., and Zhang, W. (2007). High-level expression of the recombinant hybrid peptide cecropinA(1-8)magainin2(1-12) with an ubiquitin fusion partner in Escherichia coli. Protein Expr. Purif. 55, 175-182.

Yang, D., Biragyn, A., Kwak, L. W., and Oppenheim, J. J. (2002). Mammalian defensins in immunity: more than just microbicidal. Trends Immunol. 23, 291-296.

Yang, D., Chertov, O., and Oppenheim, J. J. (2001). Participation of mammalian defensins and cathelicidins in anti-microbial immunity: receptors and activities of human defensins and cathelicidin (LL-37). J. Leukoc. Biol. 69, 691-697.

Yang, X., Xiao, Y., Wang, X., and Pei, Y. (2007). Expression of a novel small antimicrobial protein from the seeds of motherwort (Leonurus japonicus) confers disease resistance in tobacco. Appl. Environ. Microbiol.73, 939-946.

Yeung, A. T., Gellatly, S. L., and Hancock, R. E. (2011). Multifunctional cationic host defence peptides and their clinical applications. Cell Mol. Life Sci. 68, 2161-2176.

Zasloff, M. (2002). Antimicrobial peptides of multicellular organisms. Nature 415, 389-395.

Zhou, C., Qi, X., Li, P., Chen, W. N., Mouad, L., Chang, M. W., Leong, S. S., and Chan-Park, M. B. (2010). High potency and 
broad-spectrum antimicrobial peptides synthesized via ringopening polymerization of alphaamino acid- $N$-carboxyanhydrides. Biomacromolecules 11, 60-67.

Conflict of Interest Statement: The authors declare that the research was conducted in the absence of any commercial or financial relationships that could be construed as a potential conflict of interest.

Received: 16 September 2011; paper pending published: 28 September 2011; accepted: 01 November 2011; published online: 22 November 2011.

Citation: Silva ON, Mulder KCL, Barbosa AEAD, Otero-Gonzalez AJ, LopezAbarrategui C, Rezende TMB, Dias SC and Franco OL (2011) Exploring the pharmacological potential of promiscuous host-defense peptides: from natural screenings to biotechnological applications. Front. Microbio. 2:232. doi: 10.3389/fmicb.2011.00232

This article was submitted to Frontiers in Antimicrobials, Resistance and Chemotherapy, a specialty of Frontiers in Microbiology.
Copyright (C) 2011 Silva, Mulder, Barbosa, Otero-Gonzalez, LopezAbarrategui, Rezende, Dias and Franco. This is an open-access article subject to a non-exclusive license between the authors and Frontiers Media SA, which permits use, distribution and reproduction in other forums, provided the original authors and source are credited and other Frontiers conditions are complied with. 